\title{
O gasto social do governo de Mato Grosso do Sul (2013-2017)
}

\author{
The social expenditure of the government of Mato Grosso do Sul (2013-2017) \\ El gasto social del gobierno de Mato Grosso do Sul (2013-2017)
}

\author{
Francis Régis Gonçalves Mendes Barbosa ${ }^{1}$ \\ Jandir Ferrera de Lima²
}

Recebido em 20/06/2019; revisado e aprovado em 11/12/2019; aceito em 13/01/2020

DOI: http://dx.doi.org/10.20435/inter.v22i2.2623

\begin{abstract}
Resumo: O objetivo desta pesquisa foi quantificar e analisar o gasto social do governo de Mato Grosso do Sul no período de 2013 a 2017. Na mensuração do gasto social, foram contempladas as funções Educação, Cultura, Saúde, Saneamento Básico, Trabalho, Assistência e Previdência Social, Habitação e Urbanismo, Segurança Pública, Judiciária e Essenciais à Justiça, Gestão Ambiental, Ciência e Tecnologia e Transportes. Os resultados demonstraram que o gasto social do governo de Mato Grosso do Sul aumentou sua participação relativa na receita total, na receita corrente líquida e na despesa total, em termos reais e per capita, a despeito do deficit orçamentário do governo. A prioridade do governo estadual foi o gasto social, associado a externalidades positivas, o que contribuiu para a melhoria da qualidade de vida da população dessa unidade federativa.
\end{abstract}

Palavras-chave: federalismo fiscal; bens públicos; descentralização político-administrativa; descentralização fiscal.

\begin{abstract}
This research aimed to quantify and to analyze the social spending of the government of Mato Grosso do Sul in the period from 2013 to 2017. In the measurement of social expenditure, the functions Education, Culture, Health, Basic Sanitation, Work, Social Assistance and Security, Housing and Urbanism, Public Security, Judiciary and Essential to Justice, Environmental Management, Science and Technology, and Transport were considered. The results demonstrated that social spending of the government of Mato Grosso do Sul increased its relative participation in the total revenue, in the net current revenue and in the total expenditure, in real and per capita terms, despite the government's budget deficit. The priority of the state government was social spending, associated with positive externalities, which contributed to the improvement of the population's quality of life of this federative unit.

Keywords: fiscal federalism; public goods; political-administrative decentralization; fiscal decentralization.

Resumen: El objetivo de esta investigación fue cuantificar y analizar el gasto social del gobierno de Mato Grosso do Sul en el período de 2013 a 2017. En la medición del gasto social se contemplaron las funciones Educación, Cultura, Salud, Saneamiento Básico, Trabajo, Asistencia y Seguridad Social, Vivienda y Urbanismo, Seguridad Pública, Judicial y Esencial a la Justicia, Gestión Ambiental, Ciencia y Tecnología y Transportes. Los resultados demostraron que el gasto social del gobierno de Mato Grosso do Sul aumentó su participación relativa en el ingreso total, en el ingreso corriente neto y en el gasto total, en términos reales y per cápita, a pesar del déficit presupuestario del gobierno. La prioridad del gobierno estatal fue el gasto social, asociado a externalidades positivas, lo que contribuyó a la mejora de la calidad de vida de la población de esa unidad federativa.
\end{abstract}

Palabras clave: federalismo fiscal; bienes públicos; descentralización político-administrativa; descentralización fiscal.

\section{INTRODUÇÃO}

A economia brasileira vem mostrando sinais de esgotamento do crescimento econômico desde o ano de 2013, situação confirmada pela deterioração dos indicadores econômicos. A taxa de crescimento real do produto interno bruto (PIB) passou de uma média de 3\% em 2013 para $-3,5 \%$ entre 2015 e 2016, recuperando-se para 1\% em 2017. A variação real do PIB per capita caiu de 2,1\% em 2013 para-4,2\% em 2016 e 0,2\% em 2017. A taxa média de desocupação passou de

\footnotetext{
${ }^{1}$ Universidade Estadual de Mato Grosso do Sul (UEMS), Ponta Porã, Mato Grosso do Sul, Brasil.

${ }^{2}$ Universidade Estadual do Oeste do Paraná (UNIOESTE), Toledo, Paraná, Brasil.
} 
6,5\% no último trimestre de 2014 para 11,8\% no último trimestre de 2017, alçando o patamar de mais de dois dígitos desde o primeiro trimestre de 2016 (BANCO CENTRAL DO BRASL [BCB], 2018).

Seguindo a tendência de deterioração da economia brasileira, as contas públicas sofreram também impactos negativos. O resultado primário do governo central passou de $1,4 \%$ do PIB em 2013 para-2,6\% do PIB em 2016 e 2017 (BCB, 2018). Espera-se que essa deterioração das finanças do governo federal reflita também nos governos estaduais e municipais, por meio da queda da arrecadação desses entes.

O federalismo fiscal pressupõe a descentralização político-administrativa e tributária, transferindo aos entes subnacionais algumas atribuições antes desempenhadas pelo governo central, inclusive nas áreas sociais, com a contrapartida dos recursos para financiá-las. Cumpre, então, analisar como o gasto social governamental foi afetado pelo mau desempenho econômico, uma vez que ele é um parâmetro da ação pública nas áreas sociais (ROCHA; FERRERA DE LIMA; PIACENTI, 2011). Diante do exposto, o objetivo da pesquisa foi quantificar e analisar o gasto social do governo de Mato Grosso do Sul no período de 2013 a 2017. Optou-se por trabalhar com o governo de Mato Grosso do Sul pelo caráter inédito do trabalho. O período se justifica por coincidir com um período singular de crise da economia brasileira e pela disponibilidade de dados a partir do ano de 2013.

Como gasto social, entendem-se aqueles destinados à melhoria das condições de vida da população, em curto ou longo prazo (FERNANDES et al., 1998). Trabalhou-se com a ótica da responsabilidade dos gastos, e não com a origem dos recursos. As funções de gastos contempladas como sociais foram Educação, Cultura, Saúde, Saneamento Básico, Trabalho, Assistência e Previdência Social, Habitação e Urbanismo, Segurança Pública, em conformidade com Rückert e Rabelo (2005) e Rocha, Ferrera de Lima e Piacenti (2011). Ademais, foram incluídas as funções Judiciária e Essenciais à Justiça, Gestão Ambiental, Ciência e Tecnologia e Transportes, por se constituírem áreas ligadas à provisão de bens públicos e, consensualmente, na literatura, serem apontadas como geradoras de externalidades positivas (MUSGRAVE; MUSGRAVE, 1980; REZENDE, 2006; GIAMBIAGI; ALÉM, 2011), uma inovação deste estudo na classificação de gasto social.

Os dados foram obtidos da base de dados da Secretaria do Tesouro Nacional chamada de Finanças do Brasil (FINBRA) e foram deflacionados, ano a ano, pelo Índice Geral de PreçosDisponibilidade Interna (IGP-DI) da Fundação Getúlio Vargas, de acordo com a recomendação de Fernandes et al. (1998).

O trabalho está estruturado em cinco seções, contando esta introdução. Na segunda seção, é apresentado o arcabouço teórico acerca das funções econômicas do governo, quais sejam: alocativa, distributiva e estabilizadora. Na terceira, são apresentados os elementos teóricos, problemas e vantagens associados ao federalismo fiscal brasileiro. Na quarta seção, são feitas a análise e a discussão do gasto social do governo de Mato Grosso do Sul e, por fim, na quinta seção, são tecidas as conclusões do estudo.

\section{AS FUNÇÕES ECONÔMICAS DO GOVERNO}

Num sistema federativo, a gestão de todas as funções do governo é compartilhada entre todos os entes, dependendo do grau de autonomia conferido a eles (ROCHA; FERRERA DE LIMA; PIACENTI, 2011). O governo desempenha as seguintes funções econômicas: alocativa, distributiva e estabilizadora (MUSGRAVE; MUSGRAVE, 1980; REZENDE, 2006). 
A função alocativa é requerida nas situações em que a alocação de recursos via determinação de preço de mercado não conduz a uma maior eficiência alocativa (MUSGRAVE; MUSGRAVE, 1980; REZENDE, 2006). Por exemplo, nas atividades relacionadas à expansão da infraestrutura de estradas, os benefícios sociais e econômicos superam os benefícios individuais do empreendimento (externalidades positivas), justificando a intervenção do governo (GIAMBIAGI; ALÉM, 2011).

Outro caso que justifica a atuação do governo são os problemas associados à satisfação das necessidades coletivas, nos quais as características especiais de demanda de alguns bens tornam o mecanismo de determinação de preço de mercado incapaz de orientar a alocação desses recursos, os chamados bens públicos. Tais bens são não indivisíveis (o acesso é disponível a todos) e não rivais (o acesso por parte de um indivíduo ou grupo não impede o acesso aos demais), o que dificulta a produção pelo mercado, a exemplo dos serviços de segurança e justiça. Neste caso, a provisão desses bens pelo Estado é financiada por meio da tributação compulsória de recursos (REZENDE, 2006).

Musgrave e Musgrave (1980) definem um caso intermediário entre os bens públicos e privados, os denominados bens meritórios, cuja provisão é feita pelos setores público e privado, embora a provisão pudesse ser exclusivamente pública, haja vista as externalidades positivas associadas. Os exemplos clássicos são os serviços de saúde e educação.

A função alocativa está diretamente relacionada à provisão eficiente de bens públicos. A descentralização no fornecimento desses bens deve levar em consideração a limitação espacial do alcance dos benefícios, que pode variar entre nacional (segurança pública e exploração de reservas), regional (rodovias) ou local (creches e iluminação pública) (ROCHA; FERRERA DE LIMA; PIACENTI, 2011). Por critérios de eficiência, recomenda-se que a provisão seja realizada pelo ente governamental mais próximo dos beneficiários.

Com relação à função distributiva, cabe destacar que a distribuição do produto nacional depende da disponibilidade relativa dos fatores de produção e dos respectivos níveis de produtividade. Se forem admitidos somente critérios de eficiência na utilização desses fatores, a distribuição de renda no país pode não ser a socialmente desejável, impelindo o governo a intervir na economia, via política fiscal (tributação progressiva e/ou transferências), para corrigir desigualdades na distribuição do produto nacional (REZENDE, 2006).

As ações pertencentes à função distributiva devem ser de responsabilidade do governo central, dado que, se fossem realizadas por governos regionais, afetariam as decisões de localização e a mobilidade dos agentes econômicos, o que conduziria a uma ineficiência na alocação desses recursos, por não haver uma coordenação com os objetivos nacionais de redução de disparidades regionais (MUSGRAVE; MUSGRAVE, 1980).

Por fim, a função estabilizadora tem o objetivo fundamental de controlar o nível de demanda agregada para atenuar ou evitar impactos econômicos e sociais de crises de inflação ou depressão, por meio dos gastos públicos, do crédito e dos níveis de tributação (REZENDE, 2006). Essa função não pode ser exercida pelos entes subnacionais, devido à incapacidade de sustentar deficits decorrentes da política fiscal expansionista e do não controle da política monetária (ROCHA; FERRERA DE LIMA; PIACENTI, 2011).

Depreende-se que o federalismo fiscal guarda relação com as funções econômicas do governo, na medida em que a descentralização das atribuições públicas deve levar em consideração as recomendações teóricas sobre o alcance espacial dos benefícios sociais da provisão de bens públicos e os instrumentos de ação disponíveis a cada ente governamental. 


\section{O FEDERALISMO FISCAL BRASILEIRO}

A federalização consiste no compartilhamento de poder entre várias unidades federativas unidas e um governo central. No Brasil, foi institucionalizada pela Constituição Federal de 1988, em que o município foi elevado à categoria de ente federado, com autonomia nos aspectos político-administrativo e tributário (EIDT; FERRERA DE LIMA, 2007).

Os artigos constitucionais que consagraram essa autonomia, nas respectivas áreas de atuação, são os seguintes: auto-organização político-administrativa municipal (art. 18), Lei Orgânica dos Municípios (art. 29) e política de desenvolvimento urbano municipal (art. 182); competências administrativas de atribuições comuns entre União, Estados, Distrito Federal e municípios, em assuntos como preservação de patrimônio histórico e meio ambiente (arts. 23 e 30); competências tributárias em propriedade predial e territorial urbana, transmissão "intervivos" de bens imóveis e serviços de qualquer natureza (arts. 30 e 156) (BRASIL, 1988).

Além do princípio da autonomia, outro princípio constituinte do federalismo é o da participação, entendida como a cooperação entre os entes federados no atendimento das atribuições executadas pelo Estado (ROCHA; FERRERA DE LIMA; PIACENTI, 2011).

Apesar de institucionalmente implantado, o federalismo brasileiro apresenta alguns problemas práticos, entre eles, o descompasso entre a descentralização das atribuições e os repasses necessários para custeá-las (REZENDE, 2006; EIDT; FERRERA DE LIMA, 2007; ROCHA; FERRERA DE LIMA; PIACENTI, 2011). Eidt e Ferrera de Lima (2007) destacaram que esses problemas são complexos e relacionados à extensão territorial, desequilíbrios econômicos, políticos e sociais, às regionalidades e ao agravamento fiscal.

Rezende (2006) esclarece que há três características do federalismo brasileiro que estão nas raízes do seu problema: as significativas disparidades regionais, a forte tradição municipalista e o elemento político, cabendo à União ações para a redução das disparidades regionais, embora haja conflitos entre as unidades federativas mais desenvolvidas (maior autonomia tributária) e as menos desenvolvidas (aumento das transferências constitucionais).

A forte tradição municipalista consiste na relativa independência dos municípios em relação aos estados conferida pelo sistema tributário, acompanhada por desequilíbrios na repartição da receita tributária, que dificulta a realização de reformas em prol do equilíbrio federativo. $O$ elemento político consiste no desequilíbrio de representação política entre o número de eleitores das regiões e o quantitativo de representantes eleitos (REZENDE, 2006).

Para sanar o problema do descompasso entre a descentralização de atribuições e os recursos fiscais para financiamento, foram criadas as transferências intergovernamentais (EIDT; FERRERA DE LIMA, 2007). Apesar do esforço, o mecanismo ampliou os já existentes desequilíbrios na partilha fiscal entre os entes federativos, haja vista que diminuiu a fiscalização por parte do contribuinte, devido ao incremento da receita da maioria dos entes (à exceção dos mais industrializados, cujas receitas de Imposto sobre Circulação de Mercadorias e Serviços [ICMS] são significativas) e aos critérios impróprios de cálculo do montante distribuído a estados e municípios (REZENDE, 2006).

As transferências federais privilegiaram as regiões menos desenvolvidas e os municípios de menor porte, porém não foram suficientes para alavancar os investimentos necessários para a superação do atraso dessas regiões, ao mesmo tempo em que os estados mais ricos e as regiões metropolitanas, cujas demandas da população são mais complexas, são prejudicados na partilha dos recursos (REZENDE, 2006). 
A esse respeito, Baião, Cunha e Souza (2017) verificaram a contribuição das transferências legais (Fundo de Participação dos Municípios [FPM], ICMS, Fundo de Manutenção e Desenvolvimento da Educação Básica e de Valorização dos Profissionais da Educação [FUNDEB], Sistema Único de Saúde [SUS], Compensação Financeira), das transferências voluntárias e do Programa Bolsa Família na equalização fiscal dos municípios brasileiros. Constataram que o FPM (objetivo redistributivo) e o ICMS exerceram influência negativa na equalização fiscal, ao passo que o FUNDEB, os recursos do SUS e o Bolsa Família (transferências condicionais) contribuíram para essa equalização, apesar de não terem esse objetivo, defendendo a revisão do marco legal dos diversos recursos que compõem o orçamento municipal, especialmente os com objetivos redistributivos, como o FPM.

É possível ainda que a situação fiscal do município seja decorrência de fatores controláveis, como a má gestão dos recursos, na qual a compensação via transferências implicaria incentivos perversos ao desempenho dos governos locais (CYRENNE; PANDEY, 2015).

Apesar da insuficiência das transferências em garantir o equilíbrio federativo, elas se constituem um dos meios pelos quais o governo central cumpre a função distributiva, promovendo a convergência de renda e de receitas entre as regiões pobres e desenvolvidas e o desenvolvimento territorial. Para que isso ocorra, é necessário o pacto federativo, definindo as atribuições e as fontes de custeio de cada ente federado, sensibilizando os gestores federais a liberar maior parcela de recursos aos municípios, com a extinção das emendas parlamentares e transferências voluntárias (por vezes utilizadas com fins eleitoreiros), transformando-as em repasses constitucionais (EIDT; FERRERA DE LIMA, 2007).

Para haver equilíbrio entre receitas próprias e transferências, faz-se premente uma reforma tributária ampla, com simplificação tributária e reforço dos fundos federais de investimentos nas regiões mais atrasadas, reduzindo a dependência das transferências orçamentárias (REZENDE, 2006), de forma a garantir progressividade ao sistema tributário brasileiro (LUQUINI; CRUZ; CASTRO, 2017).

A discussão teórica do federalismo brasileiro expõe que, a despeito de estar institucionalizado no país desde 1988, garantindo os mecanismos legais para a descentralização político-administrativa e financeira dos entes federados, o montante de repasses aos entes subnacionais é insuficiente perante as atribuições por eles assumidas, especialmente nas áreas sociais. Adicionalmente, os mecanismos de repasse não conseguiram reduzir as disparidades regionais e intrarregionais e, em alguns casos, agravaram-nas. Fazem-se necessárias mudanças no sistema federativo, com vistas à efetiva promoção do desenvolvimento regional e territorial e melhoria da qualidade de vida nas regiões.

\section{ANÁLISE DO GASTO SOCIAL EM MATO GROSSO DO SUL}

A análise da dinâmica dos gastos sociais dos entes federados requer contextualizá-los no âmbito da descentralização e da municipalização das políticas sociais em curso no país, num quadro de descompasso entre descentralização de atribuições e repasses fiscais, que provocou desequilíbrios federativos (RÜCKERT; RABELO, 2005; REZENDE, 2006).

É mister destacar possíveis impactos da Lei de Responsabilidade Fiscal (LRF) sobre os gastos sociais, especialmente no que diz respeito aos gastos com pessoal, cujo limite é de $60 \%$ da Receita Corrente Líquida (RCL) para estados e municípios (BRASIL, 2000). Esse limite reduziu 
a liberdade de contratação de servidores e a reestruturação de carreiras pelos entes federativos, com impactos diretos sobre a prestação de serviço público nas funções de gastos sociais, como saúde, educação, e nas transferências estaduais e municipais.

Adicionalmente, é apontado o crescimento das terceirizações e quarteirizações em áreas como educação, saúde e assistência social, cujas despesas não são consideradas nos limites de gastos com pessoal da LRF, havendo tendência de precarização do trabalho e da consequente qualidade dos serviços prestados ao público. Por fim, estados e municípios têm reduzido a parcela da RCL destinada a investimentos - grande parte deles direcionados à saúde, educação e assistência -, para cumprir as exigências da LRF (BRASIL, 2010).

Na esteira de contenção dos gastos governamentais, situa-se a Emenda Constitucional $n$. 95, de 2016, conhecida como do "teto dos gastos", segundo a qual o reajuste das despesas dos órgãos federais foi condicionado à variação do Índice de Preços ao Consumidor Amplo (IPCA) do exercício fiscal anterior, com o objetivo de reduzir o deficit primário do governo federal (BRASIL, 2016). O estado de Mato Grosso do Sul aderiu também a essa regra, nos mesmos termos da proposta federal, por meio da Emenda Constitucional estadual n. 77 (MATO GROSSO DO SUL, 2017). É esperado que tais medidas tenham impactos diretos sobre os gastos sociais, inclusive os direcionados para a saúde, educação e assistência social.

As funções de gastos consideradas como sociais foram Educação e Cultura, Saúde, Saneamento Básico, Trabalho, Assistência e Previdência Social, Habitação e Urbanismo e Segurança Pública, em conformidade com Rückert e Rabelo (2005) e Rocha, Ferrera de Lima e Piacenti (2011). Ademais, foram incluídas as funções Judiciária e Essenciais à Justiça, Gestão Ambiental, Ciência e Tecnologia e Transportes, por estarem ligadas à provisão de bens públicos e serem geradoras de externalidades positivas (MUSGRAVE; MUSGRAVE, 1980; GIAMBIAGI; ALÉM, 2011). As funções de gastos governamentais são exemplos de operacionalização de políticas públicas que, apesar de não garantirem a eficiência de tais políticas, sinalizam as prioridades e intenções governamentais (SILVA et al. 2016).

Todos os valores monetários foram deflacionados pelo IGP-DI da Fundação Getúlio Vargas, pelo índice de preço acumulado em cada ano, de acordo com a recomendação de Fernandes et al. (1998). Portanto os valores serão chamados de reais por essa característica.

O conceito de despesa considerada neste trabalho foi a "paga", que, de acordo com a Secretaria do Tesouro Nacional (BRASIL, 2018), corresponde ao último estágio da execução orçamentária. Não foram considerados os registros de pagamentos processados e não processados, pertencentes aos Restos a Pagar, por corresponderem a despesas não pagas e de exercícios fiscais anteriores.

Atendo-se à análise dos dados, a Tabela 1 apresenta a execução orçamentária do governo de Mato Grosso do Sul de 2013 a 2017. À exceção das receitas de capital, houve variação real positiva de todas as rubricas, com as receitas apresentando taxas de crescimento superiores às despesas: as taxas de crescimento das receitas totais $(37,47 \%)$ e da receita corrente líquida $(23,74 \%)$ foram superiores à das despesas totais (22,23\%). Os anos de 2015 e 2016 foram marcados por instabilidades nas receitas e das despesas, período coincidente com alguns dos piores desempenhos da economia brasileira.

As rubricas das receitas totais que apresentaram as maiores taxas de crescimento foram "Receita Patrimonial" (77,02\%), "Receita de Contribuições" (54,21\%) e "Transferências Correntes" (54,12\%), esta última relacionada às transferências recebidas do governo federal, a segunda maior 
fonte de receita corrente de Mato Grosso do Sul. Outra rubrica que teve variação considerável foi "Deduções das Receitas", de 258,53\%, em parte explicada pelo aumento das transferências do estado para os municípios. Esses números mostram o aumento da descentralização de recursos em direção a estados e municípios advindos do federalismo brasileiro, que tem impacto sobre os gastos sociais, conforme destacado por Rückert e Rabelo (2005), Eidt e Ferrera de Lima (2007), Rocha, Ferrera de Lima e Piacenti (2011).

Apesar de o resultado orçamentário do governo de Mato Grosso do Sul ter sido deficitário em todo o período, o crescimento das receitas em ritmo superior ao das despesas fez esse deficit se reduzir 60,58\% no período, passando de $\mathrm{R} \$ 188,34$ milhões em 2013 para $\mathrm{R} \$$ 74,23 milhões em 2017. Rezende (2006) e Tromben (2016) alertaram que os gastos totais e sociais do governo são influenciados pelo desempenho da economia e pela situação fiscal.

A taxa de crescimento da arrecadação do governo sul-mato-grossense está relacionada ao desempenho da economia desse estado, que, entre 2010 e 2016, cresceu em média 2,6\% ao ano, a despeito da crise econômica brasileira, em comparação com o desempenho médio nacional, de $0,43 \%$ ao ano. Tal desempenho foi influenciado pelo crescimento do setor primário estadual, cuja participação no PIB aumentou de 17,23\% em 2010 para 19,27\% em 2016, e pelo menor ritmo de desaceleração do setor secundário estadual (evoluiu de 22,61\% do PIB em 2010 para 22,59\% em 2016) comparado ao nacional (reduziu-se de 27,38\% do PIB nacional em 2010 para 21,23\% em 2016), embora a participação do setor terciário no PIB estadual tenha se reduzido de 60,16\% em 2010 para 58,14\% em 2016, na contramão do desempenho nacional, em que houve aumento da participação do setor no PIB (de 67,78\% para 73,11\%) (MATO GROSSO DO SUL, 2018).

O crescimento real do PIB nacional foi de 3\% em 2013 e desacelerou para-3,31\% em 2016, ao passo que o PIB de Mato Grosso do Sul cresceu 6,6\% em 2013 e desacelerou para -2,66\% em 2016. Em 2013, o setor primário sul-mato-grossense cresceu 14,3\%, impulsionado pelo crescimento de $16,4 \%$ da agricultura (destacadamente, a produção de milho, soja e silvicultura), contribuindo com $17,71 \%$ no valor adicionado à economia estadual. No mesmo ano, o setor secundário estadual cresceu $7,1 \%$, contribuindo com 22,10\% na formação do valor adicionado ao $\mathrm{PIB}$, com destaque para o crescimento das indústrias extrativa mineral (24,9\%), de transformação $(10,8 \%)$ e construção civil (4,5\%) (MATO GROSSO DO SUL, 2018).

Em 2016, os segmentos da economia sul-mato-grossense que apresentaram taxas favoráveis de crescimento foram produção florestal $(2,2 \%)$ - motivada pelo crescimento da indústria de papel e celulose; pesca, aquicultura e serviços relacionados (6,0\%); serviços da indústria de utilidade pública (5,3\%); serviços domésticos (13,8\%); educação e saúde mercantil (1,5\%); serviços profissionais prestados às empresas (1,8\%); e atividades imobiliárias (1,3\%) (MATO GROSSO DO SUL, 2018).

O crescimento do setor primário em 2016 só não foi favorável em virtude das perdas de produção nas culturas de milho, arroz, feijão e mandioca, provocadas por estiagens e geadas na região sul do Estado, que refletiram na queda de 14,9\% no conjunto da agricultura estadual, e pela queda na criação de bovinos e suínos no período. O desempenho dessas atividades ocasionou queda de 8,3\% na taxa de crescimento da agropecuária sul-mato-grossense em 2016 (MATO GROSSO DO SUL, 2018). 


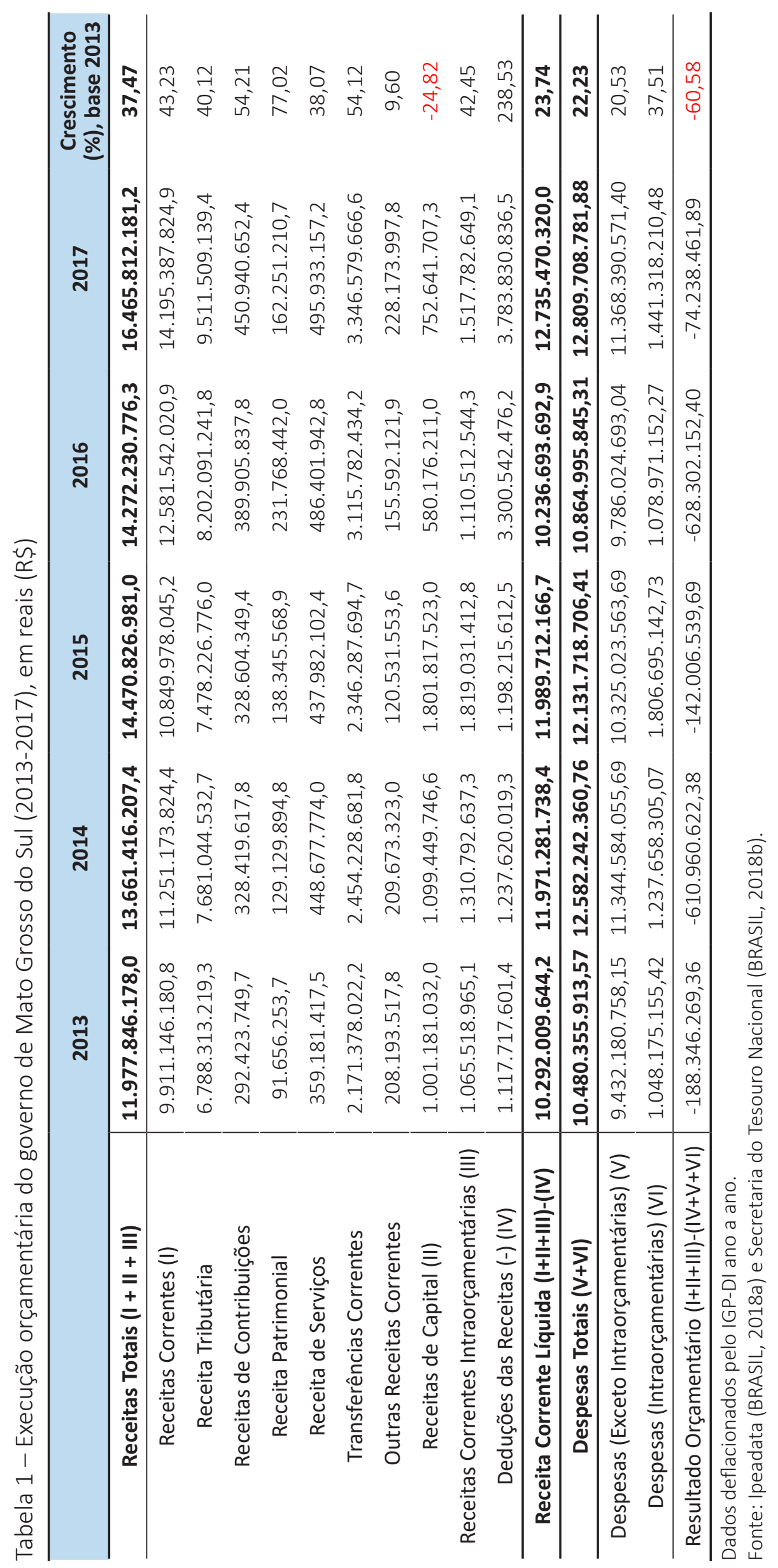


Em relação à participação dos gastos sociais nas receitas e despesas do governo de Mato Grosso do Sul, é possível observar que a Receita Total (RT) cresceu em ritmo superior à Receita Corrente Líquida (RCL) entre 2013 e 2017, fato em parte explicado pelo aumento das "Deduções das Receitas", cujo valor é deduzido da RT para a obtenção da RCL. À exceção do ano de 2015, nota-se um crescimento mais que proporcional do gasto social em relação à $R T$ e à $R C L$. Depreende-se que os gastos sociais não foram preteridos pelo governo sul-mato-grossense num quadro de deficit orçamentário, contrariamente ao alertado pela literatura. A esse respeito, Fittipaldi, Costa e Araújo (2017) apontaram a existência de um padrão incrementalista nos gastos sociais brasileiros no período de 1994 a 2014, ou seja, a burocracia estatal tende a se acomodar a padrões de intervenção observados em anos anteriores.

Tabela 2 - Participação relativa dos gastos sociais na Receita Total (RT) e Receita Corrente Líquida (RCL) do governo de Mato Grosso do Sul (2013-2017), em reais (R\$)

\begin{tabular}{|c|c|c|c|c|c|c|c|c|}
\hline \multirow[t]{2}{*}{ Ano } & \multirow{2}{*}{$\begin{array}{c}\text { Receita Total } \\
\text { (RT) } \\
\end{array}$} & \multirow{2}{*}{$\begin{array}{c}\text { R. Corrente } \\
\text { Líquida } \\
\text { (RCL) } \\
\end{array}$} & \multirow{2}{*}{$\begin{array}{c}\text { Gastos Sociais } \\
\text { (GS) }\end{array}$} & \multirow{2}{*}{\multicolumn{2}{|c|}{$\begin{array}{l}\text { (GS/RT) (GS/RCL) } \\
\text { - em \% em \% }\end{array}$}} & \multicolumn{3}{|c|}{$\begin{array}{l}\text { Taxa crescimento } \\
\text { (\%), ano-base } 2013\end{array}$} \\
\hline & & & & & & RT & $\mathrm{RCL}$ & GS \\
\hline 2013 & $11.977 .846 .178,0$ & 10.292.009.644,2 & $5.789 .057 .271,61$ & 48,33 & 56,25 & - & - & - \\
\hline 2014 & 13.661.416.207,4 & 11.971.281.738,4 & 7.050.111.108,00 & 51,61 & 58,89 & 14,06 & 16,32 & 21,78 \\
\hline 2015 & $14.470 .826 .981,0$ & 11.989.712.166,7 & $6.099 .519 .963,03$ & 42,15 & 50,87 & 20,81 & 16,50 & 5,36 \\
\hline 2016 & $14.272 .230 .776,3$ & $10.236 .693 .692,9$ & $7.623 .884 .633,03$ & 53,42 & 74,48 & 19,16 & $-0,54$ & 31,69 \\
\hline 2017 & 16.465.812.181,2 & $12.735 .470 .320,0$ & $9.030 .746 .942,65$ & 54,85 & 70,91 & 37,47 & 23,74 & 56,00 \\
\hline
\end{tabular}

Dados deflacionados pelo IGP-DI ano a ano. Fonte: Ipeadata (BRASIL, 2018a) e Secretaria do Tesouro Nacional (BRASIL, 2018b).

Adicionalmente, cabe destacar que o ano de 2015 se constituiu o primeiro ano de mandato de uma nova administração no governo do estado. Segundo a teoria do ciclo político, nos primeiros dois anos de mandato, é comum a realização de ajustes nas contas governamentais para "arrumar a casa", e, nos dois subsequentes, há um afrouxamento dessas medidas por diversos interesses, inclusive políticos (GIAMBIAGI; ALÉM, 2011). Essa teoria explica também, em parte, o crescimento percentual dos gastos sociais acima das receitas governamentais no período.

Conforme a Tabela 3, assim como foi observado em relação às receitas, no ano de 2015 foi observada uma redução da taxa de crescimento dos gastos sociais (5,36\%), que acompanhou a redução das despesas totais de 15,76\%, porém em menor proporção. Todavia, a partir de 2016, a participação dos gastos sociais nas despesas totais aumentou para mais de $70 \%$ e se manteve acima desse percentual em 2017. As taxas de crescimento em 2016 e 2017 dos gastos sociais foram de $31,69 \%$ e $56 \%$, respectivamente, enquanto as das despesas totais foram de $3,67 \%$ e $22,23 \%$, respectivamente.

A tendência de aumento da participação dos gastos sociais nas receitas e despesas governamentais foi também observada para os municípios do Rio Grande do Sul, de 1995 a 2001 (RÜCKERT; RABELO, 2005), e para os da Região Sul do Brasil (ROCHA; FERRERA DE LIMA; PIACENTI, 2011), enquanto o governo federal vem reduzindo essa participação. 
Tabela 3 - Participação relativa dos gastos sociais na Despesa Total (DT) do governo de Mato Grosso do Sul (2013-2017), em reais (R\$)

\begin{tabular}{c|ccccc}
\hline \multirow{2}{*}{ Ano } & Despesa Total & \multicolumn{2}{c}{ Gastos Sociais } & \multirow{2}{*}{ (GS/DT) em \% } & \multicolumn{2}{c}{ Taxa de crescimento (\%), ano-base 2013 } \\
\cline { 2 - 5 } & (DT) & (GS) & & DT & GS \\
\hline 2013 & $10.480 .355 .913,57$ & $5.789 .057 .271,61$ & 55,24 & - & - \\
2014 & $12.582 .242 .360,76$ & $7.050 .111 .108,00$ & 56,03 & 20,06 & 21,78 \\
2015 & $12.131 .718 .706,41$ & $6.099 .519 .963,03$ & 50,28 & 15,76 & 5,36 \\
2016 & $10.864 .995 .845,31$ & $7.623 .884 .633,03$ & 70,17 & 3,67 & 31,69 \\
2017 & $12.809 .708 .781,88$ & $9.030 .746 .942,65$ & 70,50 & 22,23 & 56,00 \\
\hline
\end{tabular}

Dados deflacionados pelo IGP-DI ano a ano.

Fonte: Ipeadata (BRASIL, 2018a) e Secretaria do Tesouro Nacional (BRASIL, 2018b).

Consoante a Tabela 4, é perceptível a evolução diferenciada dos gastos sociais em relação às despesas totais no período: os primeiros cresceram $56 \%$, enquanto as despesas totais, $22,23 \%$. Mais uma vez, o ano de 2015 representa um ponto de inflexão na maioria das funções que compõem os gastos sociais. Com exceção das funções Segurança Pública, Assistência e Previdência Social, Saúde e Saneamento, as demais funções apresentaram redução do montante de gastos. O ano de 2015, como anteriormente mencionado, foi um dos de pior desempenho da economia do país, com reflexos sobre as contas públicas.

Tabela 4 - Evolução da Despesa Total (DT), Gastos Sociais totais e por funções do governo de Mato Grosso do Sul (2013-2017), em mil reais (R\$)

\begin{tabular}{|c|c|c|c|c|c|c|}
\hline & 2013 & 2014 & 2015 & 2016 & 2017 & $\begin{array}{l}\text { Cresc. (\%), } \\
\text { base } 2013\end{array}$ \\
\hline Despesas Totais & $10.480 .355,91$ & $12.582 .242,36$ & 12.131.718,71 & $10.864 .995,85$ & $12.809 .708,78$ & 22,23 \\
\hline Gastos Sociais & $5.789 .057,27$ & $7.050 .111,11$ & 6.099.519,96 & $7.623 .884,63$ & $9.030 .746,94$ & 56,00 \\
\hline $\begin{array}{l}\text { Judiciária e } \\
\text { Essenciais à Justiça }\end{array}$ & $861.902,07$ & $1.027 .324,83$ & $949.826,39$ & $1.137 .839,37$ & $1.323 .097,12$ & 53,51 \\
\hline Segurança Pública & $756.767,10$ & $903.283,28$ & $947.837,69$ & $1.110 .847,10$ & $1.203 .730,52$ & 59,06 \\
\hline $\begin{array}{l}\text { Assistência e } \\
\text { Previdência Social }\end{array}$ & $1.548 .075,09$ & $1.768 .095,44$ & $1.894 .849,92$ & $2.338 .937,52$ & $2.884 .476,99$ & 86,33 \\
\hline Saúde & $592.248,79$ & $638.707,11$ & $663.189,78$ & $804.910,77$ & $946.594,17$ & 59,83 \\
\hline Trabalho & $12.049,23$ & $8.601,76$ & $8.549,26$ & $7.325,78$ & $8.004,86$ & $-33,57$ \\
\hline Educação & $1.162 .091,66$ & $1.213 .523,31$ & $1.198 .271,59$ & $1.511 .027,32$ & $1.706 .587,31$ & 46,85 \\
\hline Cultura & $16.890,72$ & $16.257,90$ & $12.162,82$ & $19.875,94$ & $21.398,73$ & 26,69 \\
\hline Saneamento & $16.916,12$ & $12.117,30$ & $17.607,77$ & $12.047,77$ & $40.673,31$ & 140,44 \\
\hline $\begin{array}{l}\text { Habitação e } \\
\text { Urbanismo }\end{array}$ & $30.094,03$ & $47.597,34$ & $28.692,14$ & $33.827,05$ & $35.265,67$ & 17,18 \\
\hline Gestão Ambiental & $66.942,87$ & $77.844,19$ & $28.460,27$ & $33.034,16$ & $41.518,62$ & $-37,98$ \\
\hline $\begin{array}{l}\text { Ciência e } \\
\text { Tecnologia }\end{array}$ & $27.358,09$ & $43.424,92$ & $11.291,69$ & $9.389,93$ & $6.211,95$ & $-77,29$ \\
\hline Transporte & $697.721,50$ & $1.293 .333,72$ & $338.780,64$ & $604.821,93$ & $813.187,69$ & 16,55 \\
\hline
\end{tabular}

Dados deflacionados pelo IGP-DI ano a ano.

Fonte: Ipeadata (BRASIL, 2018a) e Secretaria do Tesouro Nacional (BRASIL, 2018b). 
A análise dos gastos sociais por função revela algumas facetas importantes. À exceção da função Saneamento, as funções mais representativas em termos de montante de gastos foram também as que apresentaram as maiores taxas de crescimento no período: Judiciária e Essenciais à Justiça (53,51\%), Segurança Pública (59,06\%), Assistência e Previdência Social (86,33\%) e Educação (46,85\%). Outras funções apresentaram redução do montante de gastos, como Trabalho (-33,57\%), Gestão Ambiental (-37,98\%) e Ciência e Tecnologia (-77,29\%): apesar de pouco representativas nos gastos sociais, geram externalidades positivas que beneficiam a sociedade (MUSGRAVE; MUSGRAVE, 1980; REZENDE, 2006; GIAMBIAGI; ALÉM, 2011), sendo estratégicas para o estado de Mato Grosso do Sul.

A evolução da despesa total e dos gastos sociais per capita, por função, foram semelhantes à evolução dos gastos reais (Tabela 5). A despesa total aumentou 17,89\% no período, enquanto os gastos sociais, 50,47\%. À exceção do Saneamento, as funções que apresentaram as maiores taxas de crescimento continuaram sendo as mais representativas em termos de gastos. As funções Trabalho, Gestão Ambiental e Ciência e Tecnologia apresentaram variação negativa no período.

Tabela 5 - Evolução per capita da Despesa Total (DT), Gastos Sociais totais e por funções do governo de Mato Grosso do Sul (2013-2017)

\begin{tabular}{lcccccc}
\hline & $\mathbf{2 0 1 3}$ & $\mathbf{2 0 1 4}$ & $\mathbf{2 0 1 5}$ & $\mathbf{2 0 1 6}$ & $\mathbf{2 0 1 7}$ & $\begin{array}{c}\text { Cresc. (\%), } \\
\text { base 2013 }\end{array}$ \\
\hline Despesa Total & $4.050,74$ & $4.803,01$ & $4.631,03$ & $4.098,09$ & $4.775,49$ & 17,89 \\
\hline Gastos Sociais & $2.237,52$ & $2.691,23$ & $2.328,37$ & $2.875,60$ & $3.366,68$ & 50,47 \\
\hline Judiciária e Essenciais à Justiça & 333,13 & 392,16 & 362,58 & 429,17 & 493,25 & 48,07 \\
Segurança Pública & 292,50 & 344,81 & 361,82 & 418,99 & 448,75 & 53,42 \\
Assistência e Previdência Social & 598,34 & 674,93 & 723,32 & 882,21 & $1.075,34$ & 79,72 \\
Saúde & 228,91 & 243,81 & 253,16 & 303,60 & 352,89 & 54,16 \\
Trabalho & 4,66 & 3,28 & 3,26 & 2,76 & 2,98 & $-35,92$ \\
Educação & 449,16 & 463,24 & 457,42 & 569,93 & 636,22 & 41,65 \\
Cultura & 6,53 & 6,21 & 4,64 & 7,50 & 7,98 & 22,20 \\
Saneamento & 6,54 & 4,63 & 6,72 & 4,54 & 15,16 & 131,92 \\
Habitação e Urbanismo & 11,63 & 18,17 & 10,95 & 12,76 & 13,15 & 13,03 \\
Gestão Ambiental & 25,87 & 29,72 & 10,86 & 12,46 & 15,48 & $-40,18$ \\
Ciência e Tecnologia & 10,57 & 16,58 & 4,31 & 3,54 & 2,32 & $-78,10$ \\
Transporte & 269,67 & 493,70 & 129,32 & 228,13 & 303,16 & 12,42 \\
\hline Dados
\end{tabular}

Dados deflacionados pelo IGP-DI ano a ano.

Fonte: Ipeadata (BRASIL, 2018a) e Secretaria do Tesouro Nacional (BRASIL, 2018b).

Em relação à participação relativa das funções no gasto social (Figura 1), a maior participação coube à Assistência e Previdência Social (31,94\% em 2017), seguida por Educação (18,90\%), Judiciária e Essenciais à Justiça (14,65\%), Segurança Pública (13,33\%) e Saúde (10,48\%). Observouse o aumento da participação das funções Assistência e Previdência Social, Segurança Pública e Saúde. Transporte foi a função que mais apresentou instabilidade (evoluiu de 12,05\% em 2013 para 5,55\% em 2015 e 9\% em 2017). As que tiveram as maiores quedas de participação foram Educação, Habitação e Urbanismo, Gestão Ambiental, Ciência e Tecnologia e Transportes, todas geradoras de externalidades positivas. 
Não há consenso sobre a relação direta entre os gastos totais e sociais do governo e a melhoria na qualidade de vida da população. Rodrigues e Teixeira (2010) defendem que os gastos em investimento devem ser priorizados em detrimento dos gastos com consumo, subsídios e transferências, para a promoção do desenvolvimento econômico. Silva Filho et al. (2016) apontaram a reduzida qualidade dos dispêndios municipais sociais no Rio Grande do Norte em virtude de inconsistências institucionais. Dalchiavon e Melo (2016) constataram que, em geral, os municípios paranaenses eficientes na alocação de recursos em Educação, Cultura, Saúde, Saneamento e Trabalho possuíam as menores despesas per capita nas respectivas funções.

Figura 1 -Evolução da participação relativa das funções nos gastos sociais do governo de Mato Grosso do Sul (2013-2017), em \%

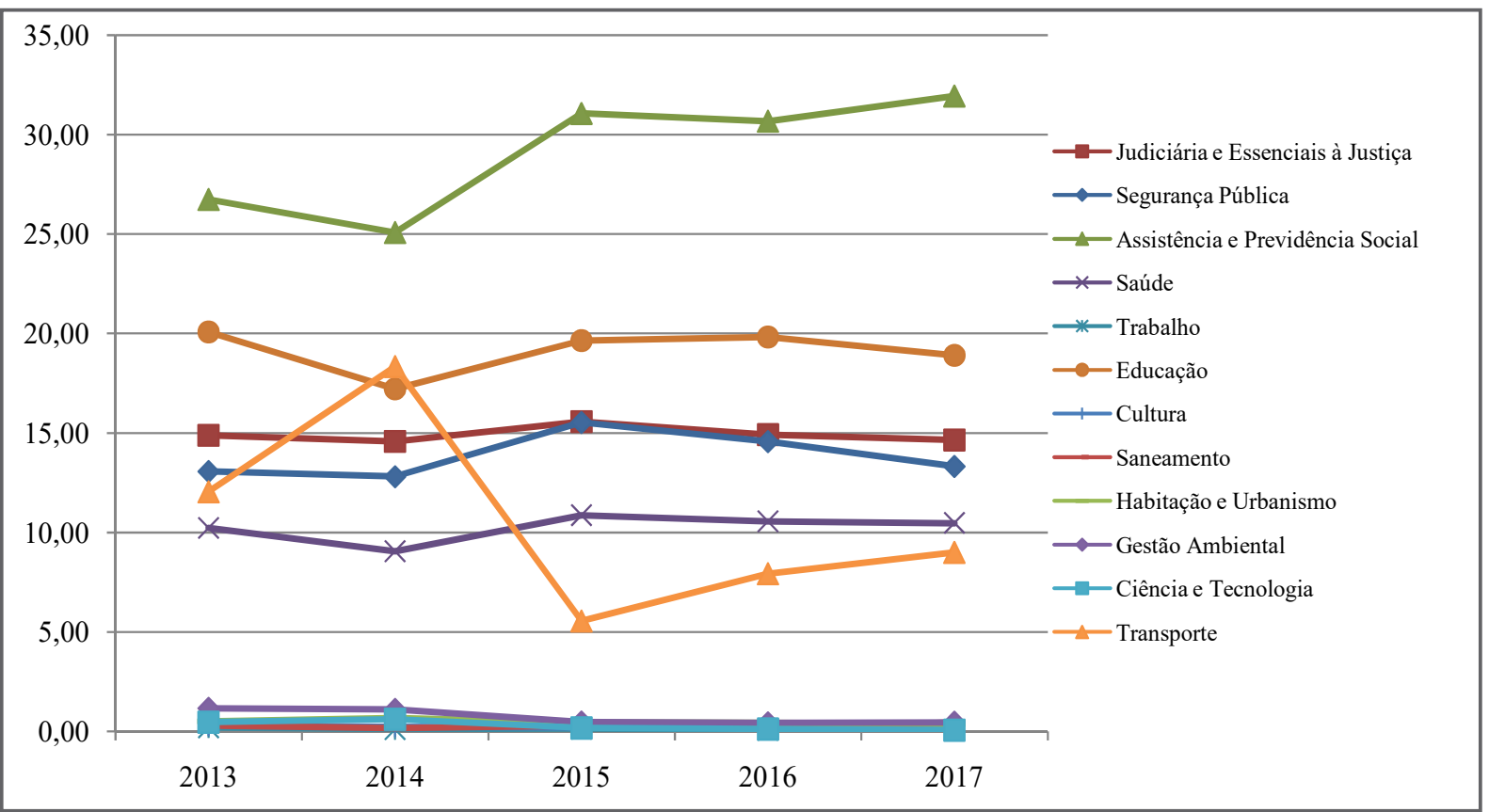

Fonte: Ipeadata (BRASIL, 2018a) e Secretaria do Tesouro Nacional (BRASIL, 2018b).

Por outro lado, há uma ampla literatura que atesta a influência dos gastos sociais na melhoria do bem-estar da população. Corrêa e Piffer (2019) constataram que os municípios de Mato Grosso do Sul que tenderam ao desenvolvimento ou círculo virtuoso apresentaram taxas de crescimento das despesas com saúde e educação acima da média estadual, enfatizando a atuação do estado nos desdobramentos do desenvolvimento.

Hiromoto (2018) verificou que os gastos sociais das três esferas governamentais contribuíram para a redução da pobreza do Brasil, em que os gastos com saúde e saneamento apresentaram maior efetividade nesse intento nos níveis federal e nos municípios, e os em educação e cultura, maior efetividade nos estados. Observou-se ainda que as diferenças regionais de desenvolvimento influenciaram no grau de efetividade da redução da pobreza: nos estados onde havia políticas focadas na melhoria da educação e distribuição de renda, o efeito do gasto social sobre a redução da pobreza foi potencializado; nos estados mais prósperos e com menor desigualdade, o efeito do crescimento da renda sobre a redução da pobreza foi maior em comparação a estados em piores condições.

Assis e Linhares (2018) constataram que a política macroeconômica nacional, especialmente o controle inflacionário pós-Plano Real e o aumento dos gastos sociais federais, foi responsável 
por aproximadamente três quartos da volatilidade total da pobreza nos estados brasileiros, entre 1976 e 2012, enquanto a educação, a menor desigualdade, e o mercado de trabalho foram fatores regionais e locais com maior peso sobre a dinâmica da pobreza.

A análise do gasto público se constitui um importante indicador do volume de recursos direcionados pelo setor público para o cumprimento das suas atribuições nas áreas de bens e serviços sociais. Dado o aumento das demandas sociais devido à urbanização e à metropolização, bem como o agravamento das disparidades regionais, tendo em vista a restrição de recursos, dimensionar os gastos sociais evidencia a estratégia de atuação do governo e sua agenda de prioridades (RÜCKERT; RABELO, 2005).

O acompanhamento e a análise dos gastos sociais se tornam ainda mais prementes num momento socioeconômico e político de recrudescimento dos receituários neoliberais de ajuste fiscal, liberalização dos mercados, privatização e financeirização da economia, com reflexos deletérios sobre os sistemas de proteção social, especialmente na saúde, educação, previdência, habitação e infraestrutura social de países pobres e em desenvolvimento (VIANA; SILVA, 2018). Tais medidas estão associadas ao aumento da pobreza, das desigualdades e das necessidades básicas insatisfeitas, que comprometem estratégias de promoção do desenvolvimento, do bemestar coletivo e de redução das disparidades regionais.

É importante destacar que há uma tendência pró-cíclica dos gastos sociais na América Latina, que se manifesta mais acentuadamente nas fases recessivas do ciclo econômico, situação enfrentada pela maioria dos seus países atualmente. O fim do ciclo das commodities e as baixas perspectivas de crescimento econômico sinalizam um cenário preocupante para os gastos sociais nos próximos anos, no qual as políticas e os programas de combate à pobreza e exclusão social devem ser defendidos e mantidos, em prol da proteção dos mais vulneráveis às crises econômicas, sob os moldes de políticas fiscais contracíclicas (TROMBEN, 2016).

Ademais, vem ocorrendo a redução da participação do gasto social do governo central brasileiro em relação a suas receitas e despesas totais nos últimos anos, processo que perfaz a descentralização das atribuições aos entes subnacionais, lógica constituinte do federalismo. Contudo, se não houver a compensação por parte de estados e municípios no sentido de recompor ou aumentar os recursos destinados a essa área, haverá o desmantelamento do sistema de proteção social do país (ROCHA; FERRERA DE LIMA; PIACENTI, 2011). Aí reside a importância do dimensionamento e da análise dos gastos sociais de estados e municípios brasileiros.

\section{CONCLUSÕES}

Este estudo quantificou e analisou o gasto social do governo de Mato Grosso do Sul no período de 2013 a 2017. Contemplou as seguintes funções como pertencentes ao gasto social: Educação e Cultura, Saúde, Saneamento Básico, Trabalho, Assistência e Previdência Social, Habitação e Urbanismo, Segurança Pública, Judiciária e Essenciais à Justiça, Gestão Ambiental, Ciência e Tecnologia e Transportes, estas quatro últimas sendo uma inovação em relação aos estudos anteriores. A inclusão dessas funções foi respaldada na teoria dos bens públicos e das externalidades. O período da análise se deveu à disponibilidade dos dados e à coincidência com um período de crise econômica brasileira e deterioração fiscal, fator que a literatura sinaliza como impacto adverso sobre a descentralização de recursos e o montante direcionado aos gastos sociais pelos governos subnacionais. 
Apesar de o resultado orçamentário do governo de Mato Grosso do Sul ter sido deficitário em todo o período analisado (evoluiu de R\$ 188,35 milhões em 2013 para R\$ 74,24 milhões em 2017), apresentando tendência de recuperação fiscal (redução de 60,58\% entre 2013 e 2017), constatou-se que o montante total do gasto social não sofreu deterioração no período, à exceção do observado no ano de 2015, apresentando taxas de crescimento acima das taxas apresentadas pela receita total, receita corrente líquida e despesa total, tanto pela análise do gasto real como pelo gasto real per capita. Os números demonstraram que o governo sul-mato-grossense não preteriu o gasto social em relação aos outros componentes de despesa, sinalizando uma agenda de prioridade: a sua participação em relação à receita total passou de 48,33\% para 54,85\%; de $56,25 \%$ para 70,91\%, em relação à receita corrente líquida; e de 55,24\% para 70,50\%, em relação à despesa total de 2013 para 2017, respectivamente.

Embora não haja consenso sobre a relação direta entre gasto social e a qualidade de vida, a maioria da literatura consultada suporta a tese de que o aumento do gasto social tenha contribuído para a melhoria da qualidade de vida da população beneficiária, na qual se inclui a população sul-mato-grossense, haja vista as externalidades positivas associadas, a contribuição para a redução da pobreza, das desigualdades e disparidades regionais e a promoção do desenvolvimento.

A despeito dos problemas apontados pela literatura que comprometem o federalismo brasileiro, e da não assertividade dos mecanismos de descentralização de recursos via transferências orçamentárias na redução das disparidades regionais e intrarregionais, defendese a recomposição dos instrumentos tributários e financeiros necessários ao desenvolvimento regional, ou seja, uma reforma tributária com simplificação tributária e reforço dos fundos federais direcionados a investimentos nas regiões mais atrasadas, reduzindo a dependência das transferências orçamentárias, promovendo o desenvolvimento regional e territorial e a melhoria da qualidade de vida nas regiões. As transferências condicionais, como os recursos do FUNDEB, do SUS e do Programa Bolsa Família, podem ser também utilizadas nesse intento, apesar de não terem esse objetivo precípuo.

Uma limitação do estudo foi o curto período de tempo utilizado, devido à disponibilidade dos dados, o que, de certa forma, compromete a análise de evolução e prioridades do governo estadual e a identificação de uma possível tendência do gasto social. Fica a sugestão de trabalhos futuros que dimensionem e analisem o gasto social dos municípios sul-mato-grossenses, o ente federativo mais próximo dos beneficiários da provisão de bens e serviços públicos.

\section{REFERÊNCIAS}

ASSIS, D. N. C.; LINHARES, F. C. Dinâmica da pobreza, mudanças macroeconômicas e disparidades regionais no Brasil. Pesquisa e Planejamento Econômico, Rio de Janeiro, v. 48, n. 2, p. 5-96, ago. 2018.

BAIÃO, A. L.; CUNHA, A. S. M.; SOUZA, F. S. R. N. Papel das transferências intergovernamentais na equalização fiscal dos municípios brasileiros. Revista do Serviço Público, Brasília, v. 68, n. 3, p. 583-610, jul./set. 2017.

BANCO CENTRAL DO BRASIL [BCB]. Indicadores econômicos consolidados. Brasília-DF, 2018. Disponível em: https://www.bcb.gov.br/pec/Indeco/Port/indeco.asp. Acesso em: 25 abr. 2019.

BRASIL. Ministério da Economia. Instituto de Pesquisa Econômica Aplicada. Macroeconômico. Brasília-DF: ipeadata, 2018a. Disponível em: http://www.ipeadata.gov.br. Acesso em: 25 nov. 2018. 
BRASIL. Secretaria do oTesouro Nacional. Sistema de Informações Contábeis e Fiscais do Setor Público Brasileiro [SICONFI]. Contas anuais. Brasília-DF, 2018b. Disponível em: https://siconfi.tesouro.gov.br/ siconfi/pages/public/consulta_finbra/finbra_list.jsf. Acesso em: 30 out. 2018.

BRASIL. Emenda Constitucional n. 95, de 15 de dezembro de 2016. Instituição do novo regime fiscal e outras providências. Brasília, 2016. Disponível em: http://www.planalto.gov.br/ccivil_03/constituicao/ emendas/emc/emc95.htm. Acesso em: 4 maio 2019.

BRASIL. Ministério da Economia. Instituto de Pesquisa Econômica Aplicada [IPEA]. Lei de responsabilidade fiscal, federalismo e políticas públicas: um balanço crítico dos impactos da LRF nos municípios brasileiros. In: CUNHA, A. S.; MEDEIROS, B. A.; AQUINO, L. M. C. (Org.). Estado, instituições e democracia: república. Brasília-DF: IPEA, 2010. p. 213-48. v. 1.

BRASIL. Lei Complementar n. 101, de 4 de maio de 2000. Lei de responsabilidade fiscal. Brasília, 2000. Disponível em: http://www.planalto.gov.br/ccivil_03/leis/lcp/lcp101.htm. Acesso em: 30 abr. 2019.

BRASIL. Constituição da República Federativa do Brasil de 1988. Brasília-DF, 1988. Disponível em: http:// www.planalto.gov.br/ccivil_03/constituicao/ConstituicaoCompilado.Htm. Acesso em: 13 nov. 2018.

CORRÊA, A. S.; PIFFER, M. Desigualdades e desenvolvimento humano municipal no estado de Mato Grosso do Sul entre os anos de 2005 e 2013. Revista Brasileira de Gestão e Desenvolvimento Regional, Taubaté, v. 15, n. 2, p. 164-73, mar. 2019.

CYRENNE, P.; PANDEY, M. Fiscal equalization, government expenditures and endogenous growth. International Tax and Public Finance, [s.I.], v. 2, n. 22, p. 311-29, 2015.

DALCHIAVON, E. C.; MELO, C. O. Eficiência dos gastos públicos em educação, saúde e trabalho para o desenvolvimento dos municípios paranaenses. Gestão e Desenvolvimento em Revista, Francisco Beltrão, v. 2, n. 2, p. 38-49, jul./dez. 2016.

EIDT, S. L.; FERRERA DE LIMA, J. Descentralização tributária no Brasil: um pacto federativo para os Municípios, Estados e a União Federal. REDES, Santa Cruz do Sul, v. 12, n. 2, p. 257-70, maio/ago. 2007.

FERNANDES, M. A. C.; OLIVEIRA, M. M. S.; ROCHA, D. C. C.; MARINHO, N. S.; RIBEIRO, J. A. C. Dimensão e acompanhamento do gasto social federal. Brasília: IPEA, 1998. (Texto para discussão n. 547).

FITTIPALDI, I.; COSTA, S. F.; ARAÚJO, C. M. C. O gasto público federal brasileiro: um perfil incrementalista? Revista do Serviço Público, Brasília, v. 68, n. 3, p. 611-30, jul./set. 2017.

GIAMBIAGI, F.; ALÉM, A. C. Finanças públicas: teoria e prática no Brasil. 4. ed. Rio de Janeiro: Elsevier, 2011.

HIROMOTO, M. A. Análise do efeito do gasto social dos governos federal, estadual e municipal sobre a pobreza no Brasil - 1988 a 2010. Pesquisa e Planejamento Econômico, Rio de Janeiro, v. 48, n. 1, p. $72-$ 102, abr. 2018.

LUQUINI, R. H.; CRUZ, A. D. S.; CASTRO, G. H. L. Verificação empírica da curva de Laffer para o Brasil entre os anos de 1996 a 2014. Economia \& Região, Londrina, v. 5, n. 1, p. 31-52, jan./jun. 2017.

MATO GROSSO DO SUL (Estado). Secretaria de Estado de Meio Ambiente, Desenvolvimento Econômico, Produção e Agricultura Familiar. Produto Interno Bruto Estadual 2010-2016. Campo Grande, MS, 2018. Disponível em: http://www.semagro.ms.gov.br/wp-content/uploads/2018/11/PIB-MS2010-2016.pdf. Acesso em: 26 abr. 2019. 
MATO GROSSO DO SUL (Estado). Emenda Constitucional n. 77, de 17 de abril de 2017. Instituição o regime de limitação de gastos e outras providências. Diário Oficial do Estado de Mato Grosso do Sul, Campo Grande, 19 abr. 2017. Disponível em: http://www.spdo.ms.gov.br/diariodoe/Index/Download/ D09392_19_04_2017. Acesso em: 29 maio 2019.

MUSGRAVE, R. A.; MUSGRAVE, P. B. Finanças públicas: teoria e prática. Rio de Janeiro: Campus, 1980.

REZENDE, F. A. Finanças públicas. 2. ed. São Paulo: Atlas, 2006.

ROCHA, F. M.; FERRERA DE LIMA, J.; PIACENTI, C. A. As despesas municipais e os gastos sociais na região Sul do Brasil. Revista Brasileira de Gestão Urbana, Curitiba, v. 3, n. 1, p. 89-102, jan./jun. 2011.

RODRIGUES, R. V.; TEIXEIRA, E. C. Gasto público e crescimento econômico no Brasil: uma análise comparativa dos gastos das esferas de governo. Revista Brasileira de Economia, Rio de Janeiro, v. 64, n. 4, p. 423-38, out./dez. 2010.

RÜCKERT, I. N.; RABELO, M. A situação das finanças públicas e a descentralização das políticas sociais nos municípios do Rio Grande do Sul, 1995-2001. Análise - Revista de Administração da PUCRS, Porto Alegre, v. 16, n. 2, p. 241-63, ago./dez. 2005.

SILVA, M. C.; FIRMINO, J. E.; SILVA, J. D. G.; BORGES, E. F. Ranking de desempenho da execução orçamentária por funções de governo dos estados e do Distrito Federal no ano de 2013. Revista Perspectivas Contemporâneas, Campo Mourão, v. 11, n. 2, p. 21-40, maio/ago. 2016.

SILVA FILHO, L. A.; CLEMENTINO, M. L. M.; SILVA, W. G.; SILVA, A. O. F. Gasto público municipal: comparativo entre as mesorregiões e a área metropolitana do Rio Grande do Norte. Espacios, Caracas, v. 37, n. 14, p. 3, 2016.

TROMBEN, V. Gasto social y ciclo econômico en América Latina y el Caribe. Santiago: CEPAL, 2016. (Serie Políticas Sociales n. 219).

VIANA, A. L. D.; SILVA, H. P. Meritocracia neoliberal e capitalismo financeiro: implicações para a proteção social e a saúde. Ciência \& Saúde Coletiva, Rio de Janeiro, v. 23, n. 7, p. 2107-17, jul. 2018.

\section{Sobre os autores:}

Francis Régis Gonçalves Mendes Barbosa: Doutorando no programa de pós-graduação em Desenvolvimento Regional e Agronegócio nda Universidade Estadual do Oeste do Paraná (UNIOESTE), . , Toledo, PR. Mestre em Agronegócios pela Universidade Federal da Grande Dourados (UFGD). Graduado em Ciências Econômicas pela Universidade Federal de Mato Grosso do Sul (UFMS). Professor do curso de Ciências Econômicas na Universidade Estadual de Mato Grosso do Sul (UEMS). E-mail: francis_barbosa@hotmail.com, Orcid: http://orcid.org/0000-0003-4462-7668

Jandir Ferrera de Lima: Ph.D. em Desenvolvimento Regional pela Universidade do Québec (UQAC), Canadá. Mestre em Economia pela Universidade Federal da Bahia (UFBA). Bacharel em Ciências Econômicas pela Universidade de Cruz Alta (UNICRUZ). Professor do programa de pós-graduação mestrado e doutorado em Desenvolvimento Regional e Agronegócio ()e da pós-graduação em Economia () - Mestradoda Universidade Estadual do Oeste do Paraná (UNIOESTE). Pesquisador e bolsista do Conselho Nacional de Desenvolvimento Científico e Tecnológico (CNPq). Pesquisador da Fundação Araucária. E-mail: jandirbr@yahoo.ca, Orcid: http://orcid.org/0000-0002-0359-0670 